\title{
SOBRE ALGUNAS PLANTAS DE LAS YESERAS DE ALMERIA
}

\author{
R. LAZARO \& A. CASTILlo \\ Estación Experimental de Zonas Aridas (CSIC) \\ C/ General Segura, 1 - 04001 Almeria.
}

\begin{abstract}
RESUMEN: Se ofrecen datos corológicos y ecológicos sobre algunos táxones de interés de la flora gipsicola almeriense. Quince táxones pueden haberse citado por primera vez en la provincia.

SUMMARY: Corological and ecological data of some interesting taxa of the gypsum flora from Almería province are presented. Fifteen taxa are probably cited at the first time for Almeria province (SE of Spain).
\end{abstract}

Los terrenos yesíferos tienen en el territorio español una gran importancia, pués cubren un $7,2 \%$ del total. Aunque diversos autores se han ocupado en los últimos 50 años de la flora y vegetación gipsícola, al menos los yesos almerienses son aún insuficientemente conocidos.

Alrededor de la mitad de los táxones que siguen no los hemos encontrado citados en la provincia. Otros, principalmente característicos de esa vegetación, se han incluido por el interês que tiene precisar su corología, su rareza u otra particularidad. Los testigos de herbario se encuentran depositados en el MGC. Todas las coordenadas UTM se refieren al Huso 30 y Faja S.

Se han estudiado todos los afloramientos principales de yesos masivos. Corológicamente el área se encuentra en el sector Almeriense de la provincia Murciano-Almeriense. La proporción de litosuelos es elevada, claramente superior al $50 \%$ en varios afloramientos; en conjunto son suelos superficiales o poco profundos, pobres, sometidos a rejuvenecimiento por la erosión. El clima es en general termomediterráneo semiárido; al menos a nivel microclimático, el extremo so del área alcanza ya el termomediterráneo árido, Venta de los Yesos roza el mesomediterráneo y el afloramiento Sorbas-Los Castaños, el termomediterráneo seco.

\section{Silene colorata Poiret}

Poco frecuente (WG80). Eriales, claros de matorral, linderos; subnitrófila. Stellarietea mediae.

Guiraoa arvensis Cosson

Rara (WĢ̧1). Ribazadas, cultivos; nitrófila. Poco frecuente en la provincia.

Lepidium subulatum L.

Abundante en la mitad occidental del área (WG60, WG40, WF49). Tomillares y matorrales abiertos, heliófilos, secos; gipsófila. Lepidion subulati. 
Reseda stricta Pers.

Frecuente en la mitad oriental del área (WG70, WG80, WG81, WF89, WF99). Eriales y matorrales; gipsófila facultativa. Gypsophiletalia.

Sedum gypsicola Boiss \& Reuter

Escaso (WG80). Gipsófilo. Gypsophiletalia y Sedo-Ctenopsion.

Astragalus grossii Pau

Raro (WF99). Tomillares áridos. Teucrio-Thymetum pallescentis (ThymoTeucriion verticillati).

Dorycnium rectum (L.) Ser in DC.

Raro, orillas del Río Aguas (WG80).

Onobrychis stenorhiza Dc.

Poco frecuente (WG80, WG81, WF99). Tomillares semiáridos. Anthyllidetalia y Gypsophiletalia.

Ononis tridentata L.

Abundante en la mitad oriental del área (WG70, WG80, WG81, WG91, XGO1). Matorrales y tomillares, gipsófila. Gypsophiletalia.

Vicia sativa L. subsp. macrocarpa (Moris) Arcangeli

Rara (WG40). En cultivos, eriales, ribazadas; subnitrófila. Stellarietea mediae.

Euphorbia clementei Boiss.

Rara, dos poblaciones (WG80).

Malva nicaeensis All.

Rara (WG81, WG60). Enclaves ruderalizados. Pegano-Salsoletea.

Helianthemum alypoides Losa \& Rivas Goday

Frecuente en la mitad oriental del área (WG70, WG80, WG81, WG91, XG01, WF99), faltando en el resto. Tomillares y matorrales abiertos; gipsófila. Santolino-Gypsophiletum struthii teucrietosum turredani.

Frankenia thymifolia Desf.

Poco frecuente (WG40, WF68). En tomillares; gipsófila facultativa. Gypsophiletalia.

Valantia hispida L.

Frecuente en la mitad oriental del área (WG70, WG80, WG81, WF99).

Valantia muralis L.

Poco frecuente (WG80).

Echium creticum L. subsp. coincyanum (Lacaita) R. Fernandes Frecuente (WG60, WG70, WG81, WG91, WF68). En pastos ruderalizados.

Teucrium charidemi Sandwith

Raro (WF89). Tomillar semiárido. Anthyllidetalia. Se amplía el área

de este endemismo, hasta ahora exclusivo de la Sierra del Cabo de Gata.

Teucrium turredanum Losa \& Rivas Goday

Frecuente en la mitad oriental del área (WG70, WG81, WF81, WF89, WF99). En matorrales y tomillares. Santolino-Gypsophiletum struthii teucrietosum turredani (Lepidiion subulati, Gypsophiletalia). 
Chaenorhinum grandiflorum (Cosson) Willk.

Muy frecuente (WF49, WG40, WG60, WG70, WG80, WG81 y WG91, XG01, WF68). Pastizales terofíticos. Plantagini ovatae-Chaenorhinetum grandiflorii (Stipion capensis).

Linaria glauca L. Chaz subsp. aragonensis (Lange) Valdés Rara (WG80). Sobre roca de yeso.

Leontodon hispidus L. subsp. hispidus Raro (WG80). Pastizales.

Onopordon corymbosum Willk. subsp. corymbosum Poco frecuente (WG60, WF68). Ruderal viaria. Onopordetea acanthii.

Iris xiphium L.

Poco frecuente (WG80).

Juncus subulatus Forskal

Raro (WG80). Planta de lugares húmedos, más o menos salinos.

Aegilops neglecta Req. ex Bertol.

Poco frecuente (WG60). Subnitrófila. Brometalia rubenti-tectori.

Avena barbata Pott ex Link

Frecuente. (WG60, WG70, WG80, WG81, WG91, WF99). Eriales, medios viarios, lindes, cultivos. Stellarietea mediae.

Phalaris brachystachys Link Raro (WG80). Cultivos, bordes viarios y veredas.

Agradecemos a A. ASENSI MARFIL y B. DIEZ GARRETAS, del Dpto. de Botánica de la Fac. de Ciencias de Málaga, la ayuda prestada.

\title{
PLANTAS ARVENSES Y RUDERALES INTERESANTES DE LA PROVINCIA DE CORDOBA
}

\author{
A. PUJADAS \& J.E. HERNANDEZ BERMEJO \\ Departamento de Botánica \\ E.T.S.I. Agrónomos (Córdoba)
}

RESUMEN: Se relaciona un total de 39 especies de ecología arvense y ruderal. La mayor parte de ellas se citan por primera vez en la provincia de Córdoba.

SUMMARY: A number of 39 taxa recolected like weeds are considered. Most of them are new records for the province of Córdoba. 